Amelia Royo

Salta, Argentina

\title{
OCTAVIO PAZ ENSAYISTA: EL DISCURSO SOBRE LA HISTORIA
}

Con ser El laberinto de la soledad una obra de 1950, es interesante comprobar que suscita interpretaciones contemporáneas de mero reconocimiento complaciente, mientras que, a la luz de nuevos enfoques críticos, la valoración se sepedita al rigor del análisis. Es el caso de la tesis doctoral de Jorge Aguilar Mora (1978), cuyo aparato conceptual marxista le permite enrostrar a Paz su enclave mítico de la historia.

Más recientemente William Foster aporta una lectura semiótica que se circunscribe al texto, sin atender las reincidencias del autor que condena Aquilar Mora. Dice Foster a próposito de El laberinto...

como todo discurso verbal, pretende ser de alguna manera una hermeneutica ante el material abordado. (...)

En término de un fenómeno discursivo, la máscara se convierte en la textura del fenómeno a ser abordado por el texto.

(Foster, 1983: 118-119)

En efecto, el crítico valora la caracterización del ser nacional mejicano por un proceso metonímico de selección poética de algunos fenómenos - máscara, pachuco, hijos de la Malinche, etc. - capaces de conducir la hermenéutica del todo (Foster, 1983: 118).

Los que para Foster son rasgos que fortalecen el valor literario del ensayo, porque el autor sondea - a través de superficies - el significado profundo de lo mexicano, para Aguilar Mora denota contradicciones imperdonables por la proclividad de Paz a la explicación del fenómeno histórico a través del mito o la tradición.

Encontramos argumentos para convalidar la postura del primero en tanto éste aduce que el discurso es metafórico porque el significado subyacente no es nítido, unívoco, lato, sino que es fundamentalmente ambiguo y confuso (Foster, 1983: 120).

Lo que convalidamos no es la tesis de que un significante ambiguo es el correlato de un significado igualmente plurívoco; se trata de actualizar la premisa de que el ensayo, como forma, constituye una manera especial de conceptualización. Desde este punto de vista es 
válida la posición de Foster que advierte en el discurso de Paz el enmascaramiento que denuncia en la sociedad mejicana, ${ }^{1}$

El concepto de la soledad deviene en la concentración simbolica (...). Entonces el discurso de Paz se tensa (...) y cobra su densidad poética en la compresión de que el verbo develador conduce a un significado aún más problemático que la superficie que se propuso interpretar.

(Foster, 1983: 121)

En este sentido la práctica textual de Paz sería significante per se y esto es lo que más lo diferencia de los análisis científicos de la cultura.

Muy otra pretende ser la interpretación y crítica que ejerce Aguilar Mora ya que su lectura es diacrónica y, en ese seguimento, detecta isotopías constantes en la escritura de Octavio Paz. Algunas son trozos indelebles desde los dos primeros ensayos que avanzan en el tiempo, acentuando su fuerza semántica hasta constituir un sistema.

Una mirada panorámica del crítico deviene en marcada división de los textos: los ensayos teóricos y sobre la historiade la modemidad, por un lado; y los ensayos sobre obras poéticas y pictóricas, por el otro (A. Mora, 1978: 14).

Precisamente esta toxonomía es la que nos indujo a creer que Octavio Paz encarna el ensayista hispanoamericano por excelencia, para ilustrar lo hasta aquí demostrado sobre el fenómeno literario y sus constantes: crítica y reflexión, categorías que se incluyen recíprocamente.

Consentimos en que las reflexiones teóricas de Paz sobre la historia de México están presentadas en El laberinto de la soledad y Posdata, como su complemento forzoso. La otra vertiente de su reflexión se orienta al concepto de poesía y poema y, en este sentido, El arco y la lira comporta una presencia axial, aunque no necesariamente nutricia de la praxis crítica del autor. Pues hay mayor retroalimentación entre la reflexión sobre el poema y su quehacer poético, que entre sus críticas y esa teorización primera, tan emparentada con el concepto de arte en Heidegger. ${ }^{2}$

1. Hemos desarrollado la misma idea con motivo de caracterizar la escritura de C. Fuentes en Cambiode piel, en un estudio presentado como tarea curricular en el Seminario Andrés Bello de Inst. Caro y Cuervo en 1987: El barroquismo enmascara una trama conexa, desdibuja la narración; (...) Conchuimos que Fuentes no maneja un discurso iluminador del contenido, toca a la crítica develar su mensaje, o mimetizarse con su 'cerrada' reflexion de transcultura (A. Royo, 1987).

2 Las referencias al filosofo son constantes a lo largo del texto. Es evidente que apoya algunos de sus planteos en $E l$ ser y el tiempo, aunque nostros confrontamos con Atte y poesía y los puntos de contacto son más que significativos como lo demostraremos más adelante. 
Volviendo a los juicios de Aguilar Mora, es interesante advertir la contraposición con Foster; mientras aquél aquilitaba las propiedades del discurso como sentido en sí, éste lo desvaloriza por no referir la historia fáctica.

... de esta europeización del punto de vista adoptado por Paz, se desprende una ambigüedad fundamental en su concepción de la historia: la palabra historia designa tanto 'los hechos' como los 'signos que relatan esos hechos'; es decir la confudion entre la historia como un hecho y la historia como discurso, como representación.

(A. Mora, 1978: 30)

Lo que Aguilar Mora desatiende es que está frente a un tipo de práctica textual - el ensayo - que intrínsecamente puede desconocer patrones de interpretación histórica, o mejor, optar por el que más le plazca como hace Pazal explicar la identidad por recurrencia al mito, a la otredad o a la analogía.

Aparentemente la búsqueda central de 'El laberino' consiste en sustentarque el origen es lo verdaderamente legútimo (...) ... en realidad se habla solo de raiz mítica, de la tredición como un elemento inmutable, como una identidad que dejo de evolucionar en determinado momento y espera así su reincorporación.

(Aguilar Mora, 1978: 39)

Uno de los procedimientos discursivos de Octavio Paz es la correspondencia analógica, ajena a la regencia racional de las causas sobre los efectos. La prosa del poeta mexicano es tan poco lógica como lo es su poesía, y esto es consecuente con lo que adelantamos sobre ensayo como forma. La descripción que citamos va más allá de lo que nuestro análisis busca, pero es ilustrativa de lo que el crítico - Aguilar Mora - pretende desacreditar cuando le exige una lógica de dialéctica-histórica.

... la prosa de Paz tiene rasgos de un conjuro: juegos de ecos, simetrías verbales y conceptuales, reieraciones, elipsis; es precisa y azarosa a la vez, como una partida de ajedrez (...); juego conceptual que se desvanece no en circulo, ni en espiral, ni en linea recta, sino en una instancia poblada de ecos.

(Benavides, 1979: 12)

La críticade Aguilar Mora es aguda y acaso cierta, pero está urgida de ortodoxia marxista y desde esa perspectiva denota la analogía de la historia con el laberinto porque entraña la concepción mítica de etemo retomo o tiempo circular. Nada más urticante para el pensamiento marxista que el nihilismo de quienes apoyan la identidad de los pueblos en la inmaterialidad de la Idea. 
Mito, forma, ser, origen, son unas de las cuantas ideas con las que el nihilismo en este libro va a desvalorizar los enunciados reales.

(Aguilar Mora, 1987: 49)

Estas ideas aparecen transcriptas mediante motivos que, a veces no guardan relación entre sí, pero, indirectamente apuntan a una imagen última. La profusión de motivos permite una doble lectura de El laberinto de la soledad, desde el punto de vista de su estructura: una como un ensayo unitario cuyas partes se condensan en el lexema núcleo del sintagma que titula el texto - laberinto - y la otra, como el conjunto de ocho ensayos independientes, aunque globalizados en el apéndice que rescata el otro polo del sentido ya, nominado en la titulación - soledad .

La posibilidad de ensamblar los motivos como estructuradores de una unidad, nos inclina a tomar el texto de Paz como un universo de sentido que no sólo se proyecta más allá de cada microestructura de aparente autonomía, sino que se extiende hasta reaparecer en ensayos posteriores, como lo probaremos al abordar Posdata.

El motivo de la orfandad que inspira el tono descriptivo de El pachuco yotros extremos, es objeto de trasiego hacia el cuarto fragmento, ya que Los hijos de la Malinche explica el origen de la actitud hermética y desconfiada del mexicano, fuera y dentro de su país. Luego /soledad/ funciona como una manifestación del sentimiento de huérfano o bastardo que enraíza al mexicano con el origen, transponiendo la historia hasta encontrarse con el mito.

En todos lados el hombre está solo. Pero la soledad del mexicano, bajo la gran noche de piedra de la Aliplanicia, poblada todavia de dioses insaciables...

(O.Paz, 1982: 18)

La vivencia popular rescata símbolos de la mitología precolombina, de la fusión étnica durante la Conquista y del advenimiento de los credos cristianos. Por eso Cuauhtémoc, la Malinche y la Virgen de Guadalupe configuran mitemas del entramado al que acude Paz en su búsqueda del origen de la soledad.

Elmisterio del paradero de sus restos es una de nuestras obsesiones (se refiere a Cuauhtémoc). Encontrarlo significa nada menos que volver a nuestro origen, reanudar nuestra filiacion, romper la soledad. Resucitar.

(O. Paz, 1982: 76)

Un intento por recuperar el orden sintagmático del texto sugiere que los títulos intermedios - Máscaras mexicanas y Todos santos, día de muertos - conforman, con el primero, una trilogía descriptiva poblada de motivos que nos remiten a realidades últimas como objeto de reflexión (de Toro, 1979: 402). 
El tratamiento de las máscaras como figura de la tendencia a la formalidad en la ontología mexicana es ya una isotopía, no sólo en el universo discursivo de Paz, sino en el texto de su cultura. En este caso, el motivo apunta a semantizar la soledad misma.

... el mexicano es un hombre que se esfierza por ser formal y que muy fácilmente se convierte en un formulista.

(O. Paz, 1982: 28)

Esta adherencia a la forma lo aleja y aísla en el ensimismamiento de la soledad.

El mexicano siempre esta lejos, lejos del mundo y de los demás. Lejos también de si mismo.

(Ibid.: 26)

Como contrapartida del encierro que supone la sujeción a las máscaras de la forma, la fiesta es el motivo que aparece con el sentido de ruptura de esa muralla ocultadora del yo.

Las conductas del mexicano frente a la instancia de la muerte o ante sus signos, entronca antitéticamente con la tradición ritual de los antiguos mexicanos. La frontera entre fiesta y culto a la muerte se diluye en la evocación del rito, acaso porque en ambos subyace un sema en común por relación dialéctica: la vida.

La presion de nuestra vitalidad, constreñida a expresarse en formas que la traicionan, explica el carácter montal, agresivo o suicida, de nuestras explosiones. Cuando estallamos, además rozamos el vértice de la vida. Y alli, en la altura de este frenesí, sentimos el vértigo: la muerte nos atrae.

(Ibid.: 52)

Si bien el texto ofrece la alternativa de proseguir su orden, entendemos pertinente buscar aquí el ensemblaje semántico con el otro ensayo de Paz que, desde el título, plantea su naturaleza participativa de uno previo. Posdata, como significante, implica secundariedad respecto de un texto que precede su carácter de aporte; como tal, la obra homónima de $\mathrm{O}$. Paz es una posdata a El laberinto, de cuyo contenido es prolongación y crítica, según palabras del propio autor.

En efecto, si El laberinto de la soledad, concebido en 1949, abarca períodos de la historia cultural mexicana: Conquista, Colonia, Independencia y Reforma, Posdata supone un avance en la cronología ya que analiza la historia contemporánea de México en visión retrospectiva, desde los episodios sangrientos de 1968 hasta la Revolución de 1910.

De lo que se trata es de encontrar las redundancias y reiteraciones en las que cae el autor por cuanto éstas delatan determinados significados afirmadores de un sentido. 
En el eje diacrónico, la Revolucion condensa la circunstancia histórica que oficia de gozne entre el pasado colonial y el presente de fracaso político del proceso revolucionario.

Octavio Paz pone el acento en el carácter crítico de su reflexión sobre el presente mexicano cuando encara el análisis de los hechos que interpreta como culminación de un derrotero postrevolucionario. Posdata se escribe en 1969, a veinte años de distancia de $E l$ laberinto y en ambos observamos que el autor diversifica su discurso según aluda a la realidad socio-política objetiva o a la hermenéutica de los estallidos puntuales.

Así, la revolución es objeto de una discursivización bastante próxima al procedimiento expositivo de la historia, en cuanto hecho empírico, pero cobra una factura altamente literaria cuando el autor verbaliza su sentido. Sintagmáticamente aparece en el segmento De la Independencia a la revolución y permanece en dos subsiguientes, particularmente en Nuestros Días, cuya orientación crítica sirve de puente con la esencia semántica análoga de Posdata en El desarrollo y otros espejïmos.

Al ser el. discurso literario el que más sutilmente, revela el discurrir conceptual, advertimos que en esa realización, el campo semántico de /revolución/ contiene semas antitéticos como/vida/y/muerte/.

... la Revolución es una búsqueda de nosotrosmismosy un regreso a la madre. Y por eso también es una fiesta. (...) Como las fiestas populares, la Revolución es un exceso y un gasto, un llegar a los extremos, un estallido de alegria y desamparo, un grito deorfandady de júbilo, de suicidio y de vida, todo mezclado.

(O. Paz, 1982: 134)

De la misma manera que los contiene/fiesta/, tal como lo registramos páginas atrás.

Entre nosotros la fiesta es una explosion, un estallido. Muerte y vida, júbilo y lamento, canto y aullido se alian en nuestros festejos, no para recrearse o reconocerse, sino para entredevorarse (...)

Dada la crítica expresa en el discurso denotativo que Paz desarrolla al analizar la sociedad post-revolucionaria, el sentido latente que encontramos en la analogía /revolución/ - / fiesta/ es que la revolución mexicana fue un estallido de vida, pero - como toda fiesta - entrañaba muerte; ésta sería el germen de fracaso que cobró cuerpo en la institucionalización de una clase política que el autor descalifica.

Revolución en la escritura de Paz, connota /vida/ porque es ruptura con la forma, porque es desenmascaramiento de la enajenación impuesta por la Reforma; pero, esencialmente, porque es reencuentro con la madre. Lo prueba la iteratividad en la que incurre el autor a través de tópicos diferentes y abordando distintos temas. 
La Revolución mexicana es un hecho que imumpe en nuestra historia como una verdadera revelación de 'nuestro ser'.

(O. Paz, 1982: 122)

La Revolución es una súbita inmersión de México 'en su propio ser'.

(Ibid.: 134)

La explosion revolucionaria es una portentosa fiesta en la que el mexicano, borracho de si mismo, conoce al fin, en abrazo mortal, 'al otro mexicano'

Revolucion fue una brusca y mortal inmersion en 'nosotros mismos' en nuestra raiz y origen, (...)

La revolución fue un descubrimiento de 'nosotros mismos' y un regreso a los origenes, (...)

(Ibid.: 150)

El movimiento revolucionario mostro que todas las ideas y concepciones que nos habian justificado en el pasado estaban muertas o mutilaban 'nuestro ser'.

(Ibid.: 153)

La Revolución mexicana nos hizo salir de nosotrosmismosy nos puso frente a la Historia.

(Ibid.: 155)

Búsqueda y momentáneo hallazgo de 'nosotros mismos' el movimiento revolucionario transformo a México, lo hizo "otro".

Al parecer, en el sistema analógico de Paz el Ser opera como magnetismo contrífugo y centrípeto, en tanto permite la asunción de la mismidad y el advenimiento del otro como su complemento.

La identificación del esquema revolucionario con una vuelta a las raíces, con un regreso a las fuentes, con un reencuentro con las tradiciones, es el argumento que utiliza para enaltecer el hecho histórico, como superador de las instancias de Colonia, Independencia y Reforma. Pues cada una, a su tiempo, fue un progresivo despojamiento de la esencia americana que indujo la inevitable soledad del mexicano.

Tanto en El laberinto de la soledad como en Posdata la escritura adopta el discurso histórico para referir el movimiento y derivaciones del acontecer revolucionario. En rigor, muchas de las críticas que enuncia en el penúltimo tramo de El laberinto se repiten en la 
alusión del fenómeno socio-economico que rotula como desarrollo en el hipotexto ${ }^{3}$. La diferencia estriba en que en 1950 describe la evolución política como emergencia de clases, afianzamiento del capitalismo nacional y alianza del sector gubernamental con la clase obrera, mientras que en 1969 carga las tintas en la crítica a la burocracia política quintaesenciada en el Partido Revolucionario Institucional (PRI).

Todo esto explica la marcha sinuosa del Estado y su deseo de 'no romper el equilibrio'. Desde la época de Carranza, la Revolución mexicana ha sido un compromiso entre fuerzas opuestas: nacionalimo e imperialismo, obrerismo y desarrollo industrial, economía dinigida y régimen de 'libre empresa', democracia y patemalismo estatal.

(O.Paz, 1982: 161)

La caracterización bastante genérica de esa etapa mostrada por la ensayística temprana difiere de la frontalidad con que alude al PRI, veinte años después.

El partido no es una agrupación política en el sentido recto de la palabra: ni su forma de reclutamiento es democrática ni en su seno se elaboran programas y estrategias para realizarlos. Es un organismo burocrático que cumple funciones administrativas.

(O. Paz, 1985a: 50)

Otro rasgo de esta escritura que se advierte repetido entre uno y otro texto, es la tendencia al análisis del fenómeno social mexicano como colateral de situaciones de proyección más amplia. Así, la Revolución mexicana es calificada de fracaso por la incapacidad del movimiento para superar el estado de subdesarrollo en el que permanecen México y otros países de América Latina o Asia, merced al fracaso del esquema manxista del que descree por su inoperancia frente a la ingerencia política del exterior.

En Posdata, el análisis de las motivaciones específicas del movimiento estudiantil mexicano lleva a reflexionar sobre el mismo fenómeno en EE.UU. o Europa. Sin embargo, análisis y reflexión sufren un viraje del discurso de la crónica contemporánea a la explicación mítica a partir del escenario de los hechos. Tlatelolco, por su connotación épica, evoca en $\mathrm{Paz}$ todo el sustrato azteca, y la visión actual de la historia adopta el discurso con que expresa la vertiente subdesarrollada de esos dos Méxicos en que el devenir histórico dividió la nacionalidad.

Desde el punto de vista estructural, el primer acápite opera como anticipo de los posteriores. Si bien Olimpiada y Tlatelolco resume dos motivos cuyo valor sémico trasciende

Aplicamos la tipología de G. Genette expuesta en Transtexthalidad (Ob. cit.) ya que allí se describe la hipotextualidad como creación derivađa de un texto anterior y $\mathrm{O}$. Paz define a Posdata como prolongación de ese libro (El laberinto). Posdata no solamente por ponerlo al día sino por ser una nueva tentativa por descifrar la realidad (1985: 10). 
la especificidad del texto que encabeza, se impone indagar en el contexto para interpretar el sentido de la escongencia.

Históricamente, el texto transcribe los acontecimientos de octubre de 1968, la alusión a Olimpíada como evento simultáneo tiene evidente proyección en el segmento inmediato. La circunstancia de que la ciudad de México haya logrado el lauro de ser la sede internacional de la Olimpíada 1968, supone haber alcanzado - como país - el desarrollo cultural y progreso material que justifiquen tal honor.

La otra línea secuencial de la crónica contemporánea entronca con el análisis del panorama de luchas universitarias que encaran la crítica al capitalismo en muchos países de Occidente; pero esa reflexión amplia es sólo el enmarque de lo que focaliza la selección del lexema. Tlatelolco es el nombre de la plaza donde se produjo la represión sangrienta del 2 de octubre de 1968; hasta aquí el dato histórico.

Olimpíada y Tlatelolco condensan, como signos, lo que refieren como hechos convergentes en ese Méjico que es desarrollo y espejismo.

Ash́, pues, puede decirse que el movimiento estudiantily la celebracion de la Olimpiada en México fueron hechos complementarios: los dos eran signos del relativo desarrollo del país.

(O. Paz, 1985a: 39)

Nuestra observación sobre las dos versiones del discurso - histórico y poético - cobra vigencia con el propósito de retrotraer el planteo hipotético que nos ocupa: si el autor tematiza poesía e historia en el marco de la reflexión mítica, estamos en la mitad de la mostración. Los dos ensayos en que la transtextualidad expresa diferentes momentos del decurso histórico mexicano, apelan al sustrato precolombino, en su vestidura mítica, para figurativizar los emergentes puntuales - Conquista, Revolución, masacre estudiantil - como reafirmaciones de una concepción del tiempo que desdice la linealidad impuesta por la cultura occidental.

La matanza de Tlatelolco nos revela que un pasado que creíamos enterrado está vivo e imumpe entre nosotros. Cada vez que aparece en público, se presenta enmascarado y armado; no sabemos quién es, excepto que es destruccion y venganza.

(Ibid.: 40)

Anticipos como éste rompen la homogeneidad del discurso de la crónica, pero será la certeza ${ }^{4}$ de la crítica la que lo eleve al plano poético hasta redundar en aporía respecto de la veracidad histórica.

4 Dicho aquí con el sentido de efectividad discursiva. No es casual que el escritor haya elegido como final frases de tono esperanzado, en actitud de introspección contrita: La crítica nos dice que debemos aprender a disolver los idolos: aprender a disolverlos dentro de nosolros mismos. Tenemos que apiender a ser aire, sueño en libertad (Ibid.: 155). 
La macroestructura Crítica de la pirámide despliega el análisis de la realidad histórica y cultural como justivicación de la ontología mexicana. Mientras la naturaleza conceptual del planteo arroja conclusiones acerca de atraso y desarrollo como las dos caras de la sociedad mexicana, $\mathrm{O}$. Paz convoca, en su escritura más reveladora, en otro México, expresión en la que centra su verdad sobre el fenómeno social que refiere desde el mito.

Con ella pretendo designar a esa realidad gaseosa que forman las creencias, fragmentos de creencias, imágenes y conceptos que la historia deposita en el subsuelo de la psiquis social esa cueva o sótano en continua somnolencia y asimismo en perpetua fermentación.

(O. Paz, 1985a: 109)

La hipótesis de que la geografía es simbólica: México se levanta entre dos mares como una enorme pirámide trunca - excede la lógica y reproduce un juego verbal que evoca resonancias líricas de inevitable intertextualidad con Neruda, acaso porque el chileno también hace de la piedra geométrica de Macchu Picchu un interlocutor de sus interrogantes. ${ }^{5}$

Arquetipo arcaico del mundo, metaffora geométrica del cosmos, la piramide mesoamericana culmina con un espacio magnético: la plataforma-santuario. Es el eje del universo, el sitio en que se cruzan los cuatro puntos cardinales, el centro del cuadrilatero: el fin y el principio del movimiento. Una inmovilidad en la que se acaba y se reengendra la danza del cosmos.

(O. Paz, 1985a: 117)

Desde la perspectiva metodológica, es claro que una estructura significativa provee los elementos para determinarla; pero en el caso del ensayo de $\mathrm{Paz}$ esos indicios no son, precisamente, los enunciados de aproximación histórica. A través de la reseña del contenido de El laberinto de la soledad y Posdata creemos haber demostrado que, efectivamente, el autor tematiza la historia; nos queda por ver qué entraña su recurrencia al mito y la coincidente adopción de la forma poética cuando travasa la historia fáctica y situada a lo arquetípico del mito. ${ }^{6}$

5 Desde el ensimismamiento existencial, Neruda indaga en las ruinas sobre la presencia humana de otro tiempo.

Pero una permanencia de piedray de palabra;

la ciudad como unvaso se levantó en las manos

de todos, vivos, muertos, callados, sostenidos

de tanta mulerte, unmuro de tanta vida, in golpe

de pétalos de piedra: la rosa permanente, la morada:

este arrecife de colonias glaciares (Neruda, 1981: 86)

6. Análisis bastante inaccesible, por otra parte, ya que el autor desdece expresamente lo que practica en su hechura textual: ...hay orro México. No me refiero de ninguna manera a una entelequia histórica y atemporal; tampoco a un arquetipo en el sentido de Jingo de Mircea Eliade (O. Paz, 1985a: 109). 
Pese a que nos proponemos un tratamiento particularizado del libro que encara la temática de la poesía, el modo poético en que Paz inquiere en la historia nos pone ante su ensayo con actitud interrogante: ¿Cuál es, en realidad, el sentido central de su obra?, iqué significa $L$ a dialéctica de la soledad en relación con los ocho apartados que la preceden?

Si bien admitimos que, entre las partes de El laberinto, hay un principio sintagmático que las concatena y justifica, lo que el autor anexa en la unidad final cobra, de pronto, independencia parcial respecto de lo que busca concluir. Lo innegable es que, como apéndice, amplía el marco especulativo esbozado a lo largo del abordaje histórico, al tiempo que universaliza el motivo clave.

Nuestra soledad tiene las mismas raíces que el sentimiento religioso. Es una orfandad, una oscura conciencia de que hemos sido arrancados del Todo...

(O. Paz, 1982: 19)

En los casos - separación de los padres, de la Matriz o de la tierra natal, muerte de los dioses o conciencia aguda de sí - la soledad se identifica con la orfandad.

(Ibid.: 58)

Lo que empieza siendo una explicación de la personalidad del mexicano - víctima y artífice de su soledad - se vuelca a la exígesis de la soledad del hombre contemporáneo. Soledad que Paz explica por planteos psiconanalísticos - presentes ya a propósito de la pulsión de muerte que atribuye a la identidad azteca - pero fundamentalmente a través del andamiaje teórico del mito.

Por obra del Mito y de la Fiesta - secular o religiosa - el hombre rompe su soledad y vuelve a ser uno con la creacion. Y así el Mito disfrazado, oculto, escondido - reaparece en casi todos los actos de nuestra vida e interviene decisivamente en nuestra Historia: nos abre las puertas de la comunión.

(Ibid.: 190)

Con un remate de onda expansiva hacia un ámbito sin fronteras, cuesta admitir esta posdata motivada por un hecho tan desgarradoramente situado como la masacre de Tlatelolco. Un intento por interpretar la tendencia de O. Paza enmascarar la realidad con la explicación mítica, nos lleva a la reflexión sobre su discurso.

Como veremos en las demás obras de nuestro corpus, la penetración en la esencia del poema también se imbrica con el mito. Esto nos sugiere nuevos interrogantes sobre la escritura que nos ocupa: ¿mitifica la historia?, ¿poetiza el mito?, o, acaso, su poetización de la historia es la forma de convertirla en mito. Aludir a un hecho tan concreto como el holocausto del 2 de octubre de 1968, como lo hace, es el asidero de nuestras dudas.

Puede decirse que fue la aparición del otro México o, más exactamente, de uno de sus aspectos. (...) el otro México no esta 
afuera sino en nosotros: no podriamos extirparlo sin mutilamos. Es un México que si sabemos nombrarlo y reconocerlo, un día acabaremos por transfigurar: cesara de ser ese fantasma que se desliza en la realidad y la convierte en pesadilla de sangre.

(O. Paz, 1985a: 113-114)

/Aparición/,/fantasma/, /pesadilla/, son semas de esa "otredad" en que lo real se diluye por efecto de la imaginación poética esa tarde la historia visible desplego, a la manera de un códice precolombino, nuestra otra historia, la invisible (Ibid.: 116).

Para quien niega el tiempo cronológico, atribuye a las revoluciones un sustrato mítico de tiempo circular - El 'eterno retorno' es uno de los supuestos implícitos de toda teoría revolucionaria ${ }^{8}$-, cree en la vigencià de la tradición de la pirámide perpetuada en la política opresiva ${ }^{9}$ de los estratos superiores, etc., expectar la salida del laberinto resulta una contradicción flagrante.

Octavio Paz encuentra en la crítica el único antídoto para preservar la dinámica social de la petrificación político-burocrática.

Cierto, la crítica no es el sueño pero ella nos enseña a soñar y a
distinguir entre los espectros de las pesadillas y las verdaderas visiones.

(O.Paz, 1985a: 155)

7 Entre los contemporáneos de Paz, Eduardo Mallea encara la valoración de la idiosincradia nacional en Historia de una pasión argentina(1936). Lo hace reconociendo que a la esencia y vitalidad auténticas habría que buscarlas debajo de las superficies sociales urbanas, en lo que llama Argentina invisible. A pesar de que su obra precede en quince años a la de Paz, despliega aspectos que el mexicano textualiza con similares elementos léxicos. Al decir de Earle, ambos intentan una autobiografia personal de la nación (1970: 31). Veamos cómo lo expresa Mallea: Asi, pues, la primera zona visible de que se apropiaron mis ojos fue el dominio del habitante desnudo, la Argentina en su humanidad. Lo primero que miré no fue el Estado, el gobiemo, las ciencias argentinas, sino el hombre argentino, (...)

El primer sentimiento que podía tenerse ante él era extraño, porque este pueblo no se entregaba (...) había algo asesinado en esos gnipos hunanos, algo desgraciadamente sacrificado a una especie de moral inauténtica (342-343).

Qué diferencia con los hombres no ostensibles, los profiundos, los subtertíneos, los llamados a una existencia trágica en el fondo del pozo que sólo recibe la estrella, pozo solitario y sin paisaje, con su extenso abismo bajo el arco sideral, con sus altemativas de noche y sol y contratiempo, pozo grave, osciuro, pozo permanente. Los unos gámulos y contentos, los otros hilando en las noches de la llanura (...) su pertinaz silencio sinamargura a lo largo de las jornadas argentinas; los unos ricos de solemnidad, los otros, solemnes de orgullosa pobreza.. (Mallea, 1961: 365).

8 Al referirse a la revolución en su país, Paz acude a un marco según el cual todo intento revolucionario pretende restituir una edad mítica. Según esto los intentos modernos son planteos utópicos de recuperación de la edad de oro (O. Paz, 1982: 129).

9 Hecho a la imagen de la realidad política y social de México, el PRI es una burocracia jerárquica, una verdadera piramide. (...) ésta encama una realidad inaginaria; sin cesar de ser realidades políticas el PRI y el presidente son proyecciones míticas, formas en las que se condensa la imagen que nos hemos hecho del poder.(Paz, 1985a: 95). Antes ha descalificado los métodos revolucionarios en su conjunto con el argumento de que todos degeneran en burocracias. 
Este final lo reconcilia con la esencia misma de la forma que cultiva. Mítica o poética, la escritura de Paz hace de la historia un texto escribible ${ }^{10}$ en el esquema de Barthes, hecho que ratifica su condición de ensayista ${ }^{11}$.

\section{Bibliografía.}

\section{De Octavio Paz}

1982 El laberinto de la soledad, México, F. C. E.

1985 Posdata, México, Siglo Veintiuno.

\section{General}

Aguilar Mora, Jorge, La divina pareja. Historia y mito en Octavio Paz, México, Ed. Era, 1978.

Benavides, Manuel, "Claves filosóficas de Octavio Paz" en Cuademos Hispanoamericanos (343-345) ñ 11-42, Madrid, 1979.

Barthes, Roland, S/Z México, Siglo Veinituno, 1986.

Foster, David W., Para una lectura semiótica del ensayo latinoamericano, Textos representativos, Madrid, Studia Humanitatis, 1983.

Genette, Gerard, Palimsestes, París, du Seuil (Trad. Univ. Nacional de Colombia), 1979.

Mallea, Eduardo, Historia de una pasión argentina. Obras completas, Buenos Aires, Emecé, 1961.

Neruda Pablo, Antología esencial, Buenos Aires, Losada, 1981.

10 Lo escribible, por opocición a lo legible es el plus de valor que ofrece un texto en tanto y en cuanto puede ser re-escrito por el lector que abandona su papel de mero consumidor para convertirse en productor ( $O$ coproductor) del texto. (Barthes, 1986: 2).

11 No es casual que para referirse a la crisis de un estado corrupto $P a z$ haya revestido su prosa de signos que definen su confianza en la crítica y en el esritor como baluarte de una cruzada del lenguaje contra el lenguaje. (...) el ejercicio de la crítica como exploración del lenguaje y el ejercicio del lengnaje como crítica de la realidad.(...) era indispensable 'impiar' el idioma y extivpar la 'ponzoña' de la retórica oficial (...).

(...) los cimientos 'escondidos' de las instinuciones, el subsuelo 'fangoso', los animales 'viscosos'. el cemento y la sed, los corredores y los stibterráneos interminables como 'prisiones'... (O. Paz, 1985a: 77-79). 


\section{Povzetek}

\section{OCTAVIO PAZ, ESEJIST: DISKURZ O ZGODOVINI}

V izvlečku svoje magistrske naloge avtorica proučuje delo Octavia Paza kot esejista, predvsem njegove eseje povezane z zgodovino Mehike. Zbirki, v katerih se Paz ukvarja z zgodovinsko tematiko, sta Labirint samote in njegovo nadaljevanje (hipotekst po Genettu) Pripis. Royova razčlenjuje značilnosti njegove esejistike in koncepta zgodovine, dokazuje, da Paz pojmuje zgodovino $v$ povezavi $z$ mitom in problemom časa (linearnost versus cikličnost) ter razkriva bistveno odvisnost Pazove poezije in esejistike. 